
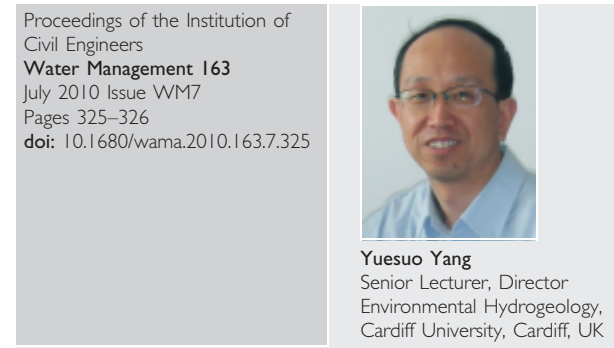

\title{
Editorial: Integrated modelling for regional water management
}

Y. S. Yang MSc, PhD

Integrated hydrological and hydrogeological modelling plays an important role in regional water management. Numerical modelling of the complicated components of the hydrological cycle and related quality characteristics can be an effective tool for decision support in water management. This is because some inherent mechanisms and system behaviours cannot easily be quantitatively measured and are not experimentally accessible in the systems of hydro-geo-atmospheres. The EU water framework directives introduced an innovative, integrated and holistic approach to the protection and management of water resources which requires integrated modelling approaches at catchment scale for its proper implementation (Yang and Wang, 2010).

\section{This issue of Water Management brings together recent} progress and advances in the numerical modelling tools used to support water management. A number of interesting and novel numerical models are used to study precipitation that could provide useful input to other hydrological and hydrogeological models. Rainfall was also linked to flooding forecast by way of numerical models. Some of the papers presented in this issue extend further studies of hydrogeological modelling for parameter estimation, saline intrusion and density dependent finite difference modelling. These works provide integrated modelling approaches for precipitation, flooding and groundwater issues, not only in quantity but also for quality.

In the first paper, Cao et al. (2010) present a new approach to determine the distributed threshold rainfall for flash flooding to support practical flood warning. It is built upon a 2D full hydrodynamic model incorporating rainfall, infiltration loss and boundary resistance. The numerical solution of the model was achieved by the second-order total-variation-diminishing version of the weighted-average-flux method along with the Harten-Lax - van Leer contact (HLLC) approximate Riemann solver for the homogeneous equations, and a Runge-Kutta scheme for the ordinary differential equations of the source terms. The applicability of the new approach is demonstrated as applied to real flash flooding-prone areas in Hunan Province, China. The threshold rainfall for flash flooding, resulting from rainfall of short durations, was quantified, which indicated a high risk of flash flooding in the local areas and prompted effective measures to avoid economic and social losses.

Creating a harmony between hydraulic constructions and a natural water environment for people to live in is a very interesting issue for watershed management. Attempts to bring two conflicting viewpoints from hydraulic engineers and ecologists into reconciliation show the practical difficulties of such a harmony. In the paper by Chou et al. (2010) the concept of emergy is introduced and used to assess the contribution of natural environment to the human economic system. The authors applied the emergy synthesis in this paper as a tool to study the catchment management approach in Taiwan. The emergy contributions of a river at different levels of the global and regional hydrological cycle are evaluated. Two new indicators for river management - river pulsing index and emergy matching index - are developed to judge the trade-off between economy and ecology.

Hydrological modelling in ungauged catchments has always been a complicated issue due to scarcity of the requisite data. In most cases, hydrologists quite often have to rely on indirect estimations based upon limited data or desk studies. Shamim et al. (2010) propose a novel approach for solar radiation estimation in ungauged catchments using readily available datasets of temperature and precipitation using a non-linear artificial neural network model. The rationale is that the extraterrestrial radiation is attenuated not only by different atmospheric processes, but also by weather phenomena. A comparison of four clear sky radiation models was made and the best model output together with temperature and precipitation data was analysed using the gamma test for best input combination and data length selection. The work showed a good calibration between the observed and estimated values using gamma test in model development.

Reliable and accurate estimation of aquifer parameters is a key process for reliable groundwater management. A number of stochastic optimisation tools are available to solve the nonlinear aquifer parameters using gradient-based techniques but also conventional stabilisation techniques. The paper by Kambhammettu and King (2010) demonstrates how to accelerate and stabilise the conventional Levenberg-Marquardt algorithm. A generalised Matlab code was developed to estimate the transmissivity and storage coefficient of the confined aquifer using residual drawdowns in an observation well. The application of the method was illustrated by two datasets from different sources and the results were compared with previous studies. The paper demonstrates that this method can estimate the parameters accurately with a more rapid convergence in comparison with the conventional algorithms. 
In the final paper of this issue, Perera et al. (2010) develop a three-dimensional mathematical model of variable density groundwater flow and miscible solute transport to investigate the saltwater contamination of a coastal aquifer in west Japan. The selected area is an agricultural region located on a coastal aquifer where the groundwater has been consumed continuously as the main water source. Groundwater quality has been deteriorated by saltwater intrusion due to the continuous exploitation of groundwater. The 3D finite difference numerical model was used by the authors to understand the saline contamination of the coastal aquifer under distributed groundwater pumping, nonuniform geology, transition zone and variation of fluid density. The model simulates the saturated and unsaturated zone groundwater flow under the influence of a variable density situation in the coastal aquifer, which can be used as a numerical tool to study saline intrusion in coastal aquifers.

\section{REFERENCES}

Cao Z, Wang X, Pender G and Zhang S (2010) Hydrodynamic modelling in support of flash flood warning. Proceedings of the Institution of Civil Engineers, Water Management 163(7): 327-340, doi: 10.1680/wama.2010.163.7.327.
Chou N-FF, Lee C-P and Ton S-S (2010) The exploration of latent river pulsing indexes in Taiwan. Proceedings of the Institution of Civil Engineers, Water Management 163(7): 341-347, doi: 10.1680/wama.2010.163.7.341.

Kambhammettu BVNP and King JP (2010) Estimation of aquifer parameters from residual drawdowns. Proceedings of the Institution of Civil Engineers, Water Management 163(7): 361-365, doi: 10.1680/wama.2010.163.7.361.

Perera EDP, Jinno K, Tsutsumi A and Hiroshiro Y (2010) A numerical study of saline contamination of a coastal aquifer. Proceedings of the Institution of Civil Engineers, Water Management 163(7): 367-375, doi: 10.1680/ wama.2010.163.7.367.

Shamim MA, Remesan R, Han D and Ghumman AR (2010) Solar radiation estimation in ungauged catchments. Proceedings of the Institution of Civil Engineers, Water Management 163(7): 349-359, doi: 10.1680/ wama.2010.163.7.349.

Yang YS and Wang L (2010) A review of modelling tools for implementation of the EU water framework directive in handling diffuse water pollution. Water Resources Management (in press), doi: 10.1007/s11269009-9526-y. 